\title{
Associations between dental care approachability and dental attendance among women pregnant with an Indigenous child: a cross-sectional study
}

Yuan Gao ${ }^{1}$, Xiangqun Ju ${ }^{2 *}$ and Lisa Jamieson ${ }^{2}$

\begin{abstract}
Background: Oral health during pregnancy is vital for both mother and child. Indigenous Australians face many barriers in accessing dental care. Service approachability is one of the key domains in accessing health services. There is little empirical evidence of the association between service approachability and dental care attendance or oral health outcome. The aim of this study is to examine the relationship between dental service approachability on dental care attendance and self-reported gum disease among South Australian women pregnant with an Aboriginal child.
\end{abstract}

Methods: Four hundred and twenty-seven women pregnant with an Aboriginal child completed questionnaires in both metropolitan and regional health settings in South Australia in 2011. Four variables related to approachability of dental services: (1) perception of need; (2) service-related health literacy; (3) oral health beliefs and; (4) trust and expectation of dental service. The association between service approachability-related factors, dental utilisation and self-reported gum disease during pregnancy were assessed using Generalised Poisson regression models, after adjusting for age, remoteness, employment status and education. Estimates were presented as adjusted prevalence ratios (APR).

Results: Most participants (85.8\%) reported a need for dental care, had positive oral health beliefs (88.3\%) and had expectations towards dental care (86.2\%). Dental service utilisation during pregnancy was low (35.7\%). Many participants (78.0\%) expressed knowing what to do if they needed dental care, while most (39.8\%) doubted that dental care would be available the next day. Poor health service literacy was identified as a risk factor for non-optimal dental attendance (APR $=0.86,95 \% \mathrm{Cl}$ 0.74-0.99). Perceived need for dental care was positively associated with self-reported gum disease (APR $=1.24,95 \% \mathrm{Cl} 1.06-1.45)$.

Conclusion: Inability to navigate the dental care system was a risk factor for poor dental attendance among South Australian women pregnant with an Aboriginal child. Perceived need for dental care was associated with gum disease.

Keywords: Aboriginal study, Access to healthcare, Approachability, Accessibility, Oral health

*Correspondence: xiangqun.ju@adelaide.edu.au

${ }^{2}$ Australian Research Centre for Population Oral Health, Adelaide Dental

School, The University of Adelaide, Adelaide, Australia

Full list of author information is available at the end of the article

\section{Background}

Indigenous Australians are those who identify as Aboriginal and/or Torres Strait Lander [1]. Indigenous Australians are the first residents of Australia, and have unique traditions, cultures, and languages [1]. However, Indigenous Australians have poorer oral health, and experience 
more oral health conditions compared with non-Indigenous Australians [2]. In the National survey of Adult Oral Health, Indigenous adults had significantly higher levels of untreated caries and missing teeth, and a lower prevalence of filled teeth, compared with non-Indigenous Australian [3].

Pregnant women are more affected by oral conditions due to hormonal and immunologic changes during pregnancy $[4,5]$. Oral conditions during pregnancy may have adverse effects on both maternal and child health outcomes. Approximately $30 \sim 47 \%[6,7]$ of pregnant women have experienced gingivitis during pregnancy, which leads to pain, uncontrollable bleeding, and difficulties in eating [8]. Periodontal disease, which stems from gingivitis, may increase risk of adverse maternal outcomes, such as systemic inflammation $[9,10]$ and preeclampsia $[11$, 12]. Maternal experience of dental caries during pregnancy is a contributing factor of early childhood caries (ECC) among children [13]. ECC affects children's eating, speech and self-confidence [13]. Experience of dental disease in childhood increases the risk of experiencing dental disease in later life [14, 15].

To maintain good oral health, annual dental check-ups are essential [16]. A higher proportion of non-Indigenous Australians attend a dentist once or more a year (60.3\%) [17] compared with Indigenous Australians (15-38\%) $[18,19]$. The low utilisation of dental care among Indigenous Australians may arise from a range of barriers Indigenous Australians face in regard to accessing timely, culturally appropriate and affordable dental care. Specifically, factors affecting dental care uptake of Indigenous Australians include cultural appropriateness of service $[20,21]$, remoteness of residency [22], cost [23] and experience of discrimination in previous receipt of health services [24].

This study is based on the theory developed by Levesque and colleagues [25] in accessing health service (see Additional file 1: Figure S1). We were especially interested in one of the domains, which is the effect of service approachability on utilisation of dental care and oral health outcomes. The service approachability is corresponding to one's ability of how to perceive the demand. [25]. Levesque and colleagues [25] noted that approachability of a health service should enable people who need the service to identify that the service exists, can be reached, and will have an impact on their health [25]. On the demand side [25], service approachability is related to one's ability to perceive the need of a service, which is constructed by one's health literacy, health belief and expectation and trust of the service. Individual health literacy is related to one's ability to access, understand and apply health information [26]. Health literacy was referred to service-related health literacy, including knowledge of system navigation, which is essential because it is the first step in interacting with the heath care environment [27]. In the context of oral health, a belief in good oral health is important to ensure dental services are utilised; such beliefs in oral health can lead to behaviour changes, for example, leading one to seek health care in the first instance. Meanwhile, parental oral health beliefs also have impacts on offspring and can predict the uptake of dental care as children grow older [28]. Finally, trust and expectation of the health service play indispensable roles in accessing health care, especially in the Indigenous Australian context. Due to long lasting legacies of colonial practises and laws, including cultural discrimination, lack of trust is one of the primary causes of poor uptake of health services among Indigenous Australians [29].

Other researchers have, in recent years, applied the model developed by Levesque [25] when working with marginalised populations, such as refugees [30] and Indigenous people [27]. However, all prior research used the model to structure reviews, not to examine the inherent associations of each of the domains with a given service utilisation and its health outcome. The aim of this study was innovative in applying the Levesque model to examine the relationship between dental service approachability on the demand side with dental care attendance and self-reported gum disease among women pregnant with an Aboriginal child in South Australia. The hypothesis was that participants with a perceived need for dental care would have a higher uptake of dental care, resulting in better oral health outcome.

\section{Methods}

\section{Study design}

This study is a cross-sectional study; and data for the study were collected during 2011-2012 as part of the baseline data collection of an early childhood caries intervention among Indigenous children in South Australia [31, 32].

\section{Setting and recruitment}

Participants were recruited through the antenatal clinic of hospitals and Aboriginal Community Controlled Health Organisations in South Australia in both metropolitan and regional locations. During data collection, researchers and staff members in health settings would approach potential participants and to provide information about the study, before obtaining written, informed consent. Convenience sampling was adopted, and criteria were: (1) Participants must be the pregnant residents of South Australia, and (2) were expecting an Aboriginal Australian baby or babies. The questionnaire included items used in the Australia national dental survey [33], 
and had been pilot tested and discussed by members in Indigenous communities and Aboriginal Maternal Infant Care workers. There were 23 domains with a wide range of oral health information in the questionnaire, including dental health, dental behaviours, dental cost, dental perceptions, oral health belief, etc. Items used in the study were oral health outcome, outcome of service utilisation, and factors related to dental care approachability [31, 32]. Recruitment commenced February 1, 2011 and ended on May 30, 2012. Participants who did not answer all questions were excluded from the study.

\section{Ethics and consent}

Ethical approval was received from the University of Adelaide Human Research Ethics Committee, the Aboriginal Health Council of South Australia, the Government of South Australia, the Human Research Ethics Committee of Child, Youth and Women's Health Service, and the Human Research Ethics Committees of participating Adelaide hospitals. The study was guided by an Indigenous reference group, World Health Organisation guidelines on ethical conduct in health research on Indigenous people [34], and local Indigenous South Australia principles. The study additionally used the Ethical Conduct in Aboriginal and Torres Strait Islander Health Research guidelines to obtain consent [35]. Parents of the participants provided signed informed consent for those being under the age of 16 years. Participants received a $\$ 50$ voucher for reimbursement of time after completing the questionnaires.

\section{Development of service-oriented model of accessing dental care}

Levesque and colleagues [25] developed a model that summarized the key determinants in accessing health service through a multi-level perspective (see supplementary Figure S1). The five dimensions that may be used to evaluate accessibility of a given health service, and include service: (1) approachability; (2) acceptability; (3) availability and accommodation; (4) affordability and; (5) appropriateness. The five dimensions reflect linear stages of a patient's journey from the initial perception of requiring health care to the final accomplishment of receiving the required treatment. These five dimensions simultaneously correspond with five abilities for consumers: (1) ability to perceive; (2) ability to seek; (3) ability to reach; (4) ability to pay and; (5) ability to engage [25]. Factors that impacted service approachability (ability to perceive) were health literacy, health belief and expectation and trust of the service.

To better fit the oral health context, we modified the model developed by Levesque (Fig. 1) [25]. Each factor was replaced by oral health-related, and dental serviceoriented determinates. These included oral health service-related health literacy, which included literacy about dental system navigation, oral health beliefs of visiting a dentist, trust and expectations of a dental service, and perceived need for dental care. According to the modified model, different stages were linear from the perception of needing care to the accomplishment of the dental patient journey.

\section{Variables}

According to the modified model, there were three factors impacting ability to perceive: dental service health literacy, oral heath beliefs, and trust and expectations of the dental provider. With the addition of perceived need for dental care, there were thus four dimensions measured in this study (see Additional file 1: Table S1 and Figure $S 2$ ).

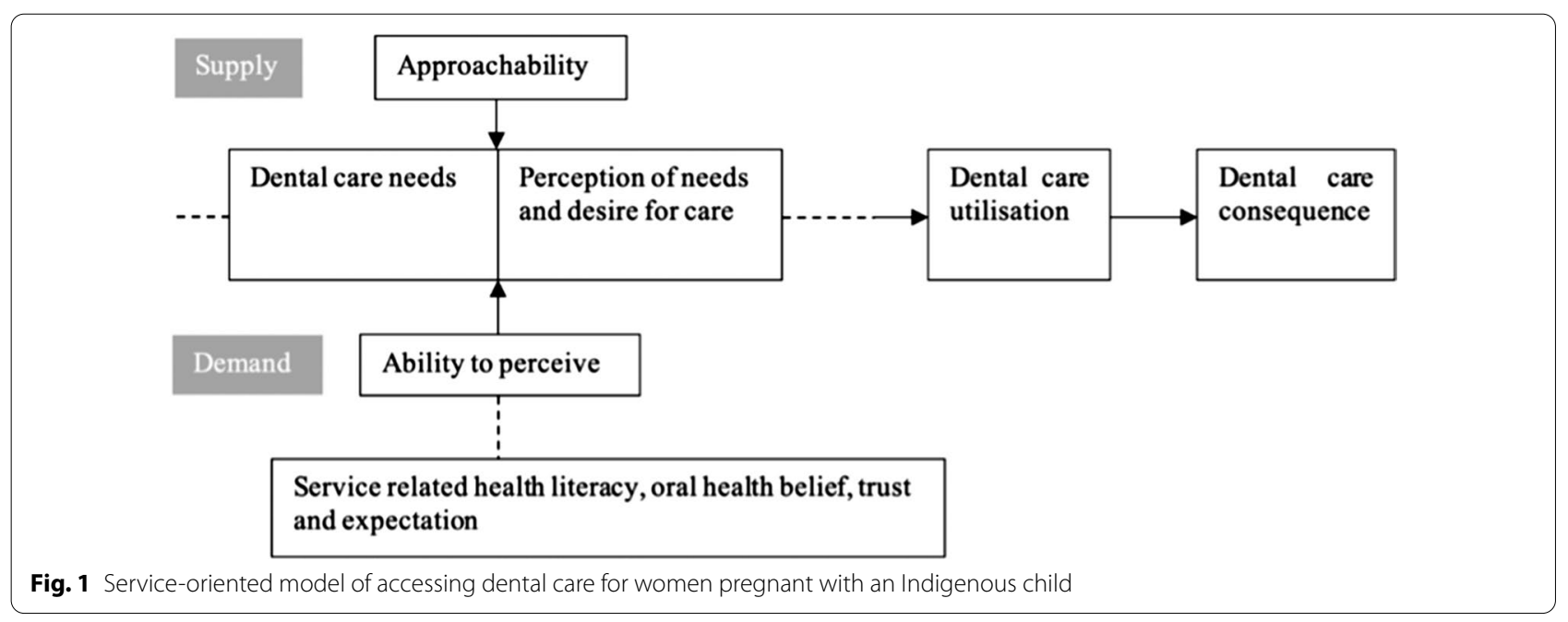


Dental service-related health literacy was measured by patient's ability to navigate to the dental health system. Dental service-related health literacy was measured by "If you needed to visit the dentist tomorrow, would you know what to do?" and "Do you think there would be a dentist able to see you tomorrow?" (response options 'yes' or 'no'). Dental health belief was measured by the question: "How important do you rate the following in relation to teeth?", with 'visiting the dentist' being the domain of interest. Response options included: 'extremely important', 'fairly important', 'doesn't matter much', 'not very important' and 'not at all important. To facilitate analysis, responses to this question were dichotomised into 'extremely/fairly important' and 'doesn't matter much/not very/not at all important'. Trust and expectation toward dental care was measured by the question "I believe going to the dentist would help my teeth", and responses were re-dichotomised as 'strongly agree' and 'not strongly agree/somewhat agree or doesn't matter much' from five sequential responds. The oral health outcome was measured by self-reported gum disease during pregnancy. The dental care utilisation outcome was measured by time of the last dental visit ( $\leq 1$ year or $12+$ months). Participant's perception of need was measured by asking: "Do you think you need to see a dentist?" (response options 'yes' or 'no').

Social-demographic variables included age, employment status, education level and geographic remoteness of residential location. The definition of the remoteness of the resident location followed the Accessibility/ Remoteness Index of Australia (ARIA+) [36], with the location subsequently categorised as "remote" and "nonremote area". Age was presented as mean values in years plus standard deviation (SD) and was re-categorised as '34 years or less' and 'over 34 years' to facilitate multivariable analysis. Education was categorised as 'no schooling, 'primary/secondary education, and 'tertiary education'. Employment status was categorised as 'employed' or 'receiving Centrelink payment/other'.

\section{Statistical analysis}

Age was presented as means and standard deviations. All other variables were categorical, and thus presented as frequency and percentage. Chi-square tests were used in bivariate analysis, while adjusted prevalence ratios and their corresponding 95\% confidence intervals were used in multivariable analysis using Generalised Poisson regression models [37] because the distribution of outcome variables was under-dispersed [38]. Factors related to service approachability (perceived need for dental care, oral health belief, dental service health literacy and trust and expectation toward service) were tested in bivariate analysis, with variables with statistically significant differences $(P<0.05)$ entered into multivariable models. Confounders were adjusted for, and included remoteness of residency, education level and employment status. Age was an additional confounder in the model involving dental attendance (Table 2), because studies have found pregnant women aged above 35 years old were more likely to access dental care [39], and we assumed that such women would be more experienced in health care seeking. Additional analyses were performed to examine the association between dental attendance and self-reported gum disease. Annual dental visit was entered into the regression model as an exposure for self-reported gum disease, and adjusted for remoteness, education and employment status. Variables with $P<0.05$ in 2 -sided $\alpha$ level were considered as being statistically significantly different in all analyses. Data were analysed using $\mathrm{R}$ version 3.6.1.

\section{Results}

A total of 554 eligible participants were invited to take part in the study, with 427 (77\%) providing consent and completing the questionnaire. The average age of participants was $25.3 \pm 5.8$ years (Table 1). Most participants reported having received primary/secondary education (70.3\%), and approximately one-third (28.1\%) had received tertiary education. Approximately $15 \%$ of participants were in current employment. The majority of participants lived in non-remote locations (86.9\%).

As shown in Table 1, 42.7\% of participants reported having experience of gum disease. Almost all participants $(96.9 \%)$ reported having seen a dentist in their lifetime. $85.8 \%$ of participants perceived a need for dental care. Of these, more than one-third (35.7\%) had visited a dentist in the previous 12 months. Most participants (88.3\%) perceived visiting a dentist to be very important. Of these, $36.7 \%$ of participants had attended for dental care in the last 12 months (Table 2). Approximately one quarter of participants (22.0\%) reported not knowing what to do if they needed to visit the dentist the next day. Just over $60 \%$ (60.2\%) of participants reported that they did not think a dentist would be able to see them the next day. Most participants (86.2\%) strongly agreed that going to the dentist would help their teeth.

Table 2 shows the unadjusted and adjusted estimates from the multivariable analysis with visiting a dentist less than 12 months ago as the outcome and the service approachability factors as exposures. With the exception of perceived need for dental care, all factors related to service approachability were associated with dental service utilisation in the unadjusted analysis. After adjusting for remoteness of residency, education level, employment status and age, only one factor remained statistically significant: "not knowing what to do if needed to make 
Table 1 Sample demographic characteristics and service approachability-related factors among women pregnant with an Indigenous child in South Australia

\begin{tabular}{|c|c|c|}
\hline & $\mathbf{n}$ & $\%(95 \% \mathrm{Cl})$ \\
\hline Total & 427 & 100.0 \\
\hline Age (mean, SD) & & $25.28 \pm 5.84$ \\
\hline$\geq 35$ years & 24 & $5.9(3.8-8.6)$ \\
\hline$<35$ years & 381 & $94.1(91.3-96.1)$ \\
\hline \multicolumn{3}{|l|}{ Education level } \\
\hline No schooling & 7 & $1.7(0.6-3.4)$ \\
\hline Primary/secondary education & 298 & $70.3(65.7-74.6)$ \\
\hline Tertiary education & 119 & $28.1(23.8-32.6)$ \\
\hline \multicolumn{3}{|l|}{ Employment } \\
\hline Job & 61 & $14.5(11.3-18.2)$ \\
\hline Other/centrelink payment & 360 & $85.5(81.8-88.7)$ \\
\hline \multicolumn{3}{|l|}{ Location } \\
\hline Non-remote & 359 & $86.9(83.2-90.0)$ \\
\hline Remote & 54 & $13.1(1.0-16.7)$ \\
\hline \multicolumn{3}{|l|}{ Oral health outcome } \\
\hline \multicolumn{3}{|c|}{ Do you have gum disease/bleeding gums? } \\
\hline Yes & 182 & $42.7(38.0-47.6)$ \\
\hline No & 244 & $57.3(52.4-62.0)$ \\
\hline \multicolumn{3}{|l|}{ Dental service utilisation } \\
\hline \multicolumn{3}{|l|}{ Have you seen the dentist before? } \\
\hline Yes & 411 & $96.9(94.8-98.4)$ \\
\hline No & 13 & $3.1(1.6-5.2)$ \\
\hline \multicolumn{3}{|l|}{ When did you last see a dentist? } \\
\hline$<1$ year & 147 & $35.7(31.0-40.5)$ \\
\hline$\geq 1$ year $(\mathrm{s})$ & 265 & $64.3(59.4-69.0)$ \\
\hline \multicolumn{3}{|l|}{ Perceiving need of dental service } \\
\hline \multicolumn{3}{|l|}{ Do you think you need to see a dentist? } \\
\hline Yes & 362 & $85.8(82.0-89.0)$ \\
\hline No & 60 & $14.2(11.0-17.9)$ \\
\hline \multicolumn{3}{|l|}{ Service-related oral health belief } \\
\hline \multicolumn{3}{|c|}{ How important do you rate the visiting dentist in relation to health? } \\
\hline Extremely/fairly important & 376 & $88.3(84.8-91.1)$ \\
\hline Doesn't matter much/Not important & 50 & $11.7(8.8-15.2)$ \\
\hline \multicolumn{3}{|c|}{ Service-related health literacy (system navigation) } \\
\hline \multicolumn{3}{|c|}{ If you needed to visit the dentist tomorrow, do you know what to do? } \\
\hline Yes & 333 & $78.0(73.8-81.8)$ \\
\hline No & 94 & $22.0(18.2-26.3)$ \\
\hline \multicolumn{3}{|c|}{ Do you think there would be a dentist able to see you tomorrow? } \\
\hline Yes & 168 & $39.8(35.1-44.7)$ \\
\hline No & 254 & $60.2(55.3-64.9)$ \\
\hline \multicolumn{3}{|l|}{ Trust and expectation } \\
\hline \multicolumn{3}{|c|}{ I believe going to dentist would help my teeth } \\
\hline Strongly agree & 367 & $86.2(82.5-89.3)$ \\
\hline Somewhat agree or don't know & 59 & $13.8(10.1-17.5)$ \\
\hline
\end{tabular}


Table 2 Percentage, prevalence ratio (PR) and 95\% Cl of visiting dentist less than 1 year among women pregnant with an Indigenous child in South Australia $(n=427)$

$\%(95 \% \mathrm{Cl}) \quad$ PR $95 \% \mathrm{Cl}^{\mathrm{a}} \quad$ APR $95 \% \mathrm{Cl}^{\mathrm{b}}$

Perceiving need of dental service

Do you think you need to see a dentist?

$\begin{array}{llll}\text { No } & 46.7(28.1-38.0) & \text { Ref } & - \\ \text { Yes } & 32.9(33.7-60.0) & 1.24(0.96-1.58) & \\ \text { Service-related health literacy (system navigation) } & & & \text { Ref } \\ \text { If you needed to visit the dentist tomorrow, would you know what to do? } & 39.9(34.6-45.4) & \text { Ref } & 0.86(0.74-0.99)^{*} \\ \text { Yes } & 14.9(8.4-23.7) & 0.39(0.24-0.64)^{* * *} & \text { Ref } \\ \text { No } & 44.0(36.4-51.9) & \text { Ref } \\ \text { Do you think there would be a dentist able to see you tomorrow? } & 0.64(0.49-0.82)^{* * *} & 0.91(0.81-1.02) \\ \text { Yes } & 28.3(22.9-34.3) & & \text { Ref } \\ \text { No } & & \text { Ref } \\ \text { Service-related oral health belief } & 0.51(0.28-0.92)^{*} & 0.93(0.77-1.13) \\ \text { How important do you rate the visiting dentist in relation to health? } & & \\ \text { Extremely/fairly important } & 36.7(31.8-41.8) & \text { Ref } \\ \text { Doesn't matter much/Not important } & 18.0(8.6-31.4) & 0.49(0.28-0.85)^{* *} & \text { Ref } \\ \text { Trust and expectation } & & & 0.91(0.77-1.09) \\ \text { I believe going to dentist would help my teeth } & 37.1(32.1-42.2) & \\ \text { Strongly agree } & 18.6(9.7-30.9) & & \end{array}$

$\mathrm{PR}$, prevalence ratio; $\mathrm{APR}$, adjust prevalence ratio

${ }^{* * *} p<0.0001, *{ }^{* *} p<0.001, *{ }^{*} p<0.05$;

${ }^{a}$ Univariable analysis without any adjustment

${ }^{\mathrm{b}}$ Reducing variable showing no statistical significance in univariable analysis and adjusting for remoteness, education level, employment and age

a visit to the dentist the next day" $(\mathrm{APR}=0.86,95 \% \mathrm{CI}$ 0.74-0.99).

Table 3 shows the analysis of service approachability factors with self-reported gum disease as the outcome variable. After adjusting for remoteness, employment status and education level, participants who perceived a need for dental care had $24 \%$ higher risk of having selfreported gum disease (APR $=1.24,95 \% \mathrm{CI} 1.06-1.45)$.

There were no statistically significant associations observed between dental attendance in the last 12 months and self-reported gum disease (Table 4).

\section{Discussion}

Our research sought to examine the relationship between dental service approachability, dental care attendance and self-reported gum disease among women pregnant with an Aboriginal child in South Australia using a modified version of the Levesque model. The findings showed that service-related factors were associated with dental attendance, which was consistent with the modified model. However, little effect was observed between service-related factors and self-reported gum disease, and no association was observed between dental attendance and self-rated gum disease. The results highlight the limitations of using the modified model in a quantitative study such as the one implemented.

Participants' ability to navigate the dental care system was the key demand-side service approachability factor in utilising dental service. Previous research findings also reported Indigenous persons with higher skills in navigating dental services have higher compliance in long term dental treatment [40]. In this case, a person's language capacity, knowing the information of location and contacts of dental clinics played an important role in the accomplishment of the dental care journey [40, 41]. However, due to the complexity of the Australian health system, many Indigenous and other socially or culturally marginalised groups struggle to adequately navigate the health system [42]. For instances, some public dental services are only available for children or young adults or government health care/concession card holders. For many states, Aboriginal people may need to contact local Aboriginal community-controlled health service first to access dental care [43]. For some Indigenous Australians, mainstream dental services (private or public) may be the only options for dental care, because dental services may not be provided by their local Aboriginal communitycontrolled health service. Barriers to successfully navigate 
Table 3 Prevalence ratio (PR) and 95\% Cl of self-reported gum disease among women pregnant with an Indigenous child in South Australia $(n=427)$

\begin{tabular}{|c|c|c|c|}
\hline & $\%(95 \% \mathrm{Cl})$ & PR 95\% $\mathrm{Cl}^{\mathrm{a}}$ & APR $95 \% \mathrm{Cl}^{\mathrm{b}}$ \\
\hline \multicolumn{4}{|l|}{ Perceiving need of dental service } \\
\hline \multicolumn{4}{|l|}{ Do you think you need to see a dentist? } \\
\hline No & $15.0(7.1-26.6)$ & Ref & Ref \\
\hline Yes & $47.3(42.0-52.5)$ & $3.15(1.71-5.82) * * *$ & $1.24(1.06-1.45)^{* *}$ \\
\hline \multicolumn{4}{|c|}{ Service-related health literacy (system navigation) } \\
\hline \multicolumn{4}{|c|}{ If you needed to visit the dentist tomorrow, would you know what to do? } \\
\hline Yes & $41.1(35.8-46.6)$ & Ref & - \\
\hline No & $47.9(37.5-58.4)$ & $1.18(0.92-1.51)$ & \\
\hline \multicolumn{4}{|c|}{ Do you think there would be a dentist able to see you tomorrow? } \\
\hline Yes & $36.3(29.0-44.1)$ & Ref & Ref \\
\hline No & $46.9(40.6-53.2)$ & $1.29(1.02-1.65)^{*}$ & $1.05(0.94-1.17)$ \\
\hline \multicolumn{4}{|l|}{ Service-related oral health belief } \\
\hline \multicolumn{4}{|c|}{ How important do you rate the visiting dentist in relation to health? } \\
\hline Extremely/fairly important & $41.8(36.7-46.9)$ & Ref & - \\
\hline Doesn't matter much/Not important & $50.0(35.5-64.5)$ & $1.19(0.88-1.62)$ & \\
\hline \multicolumn{4}{|l|}{ Trust and expectation } \\
\hline \multicolumn{4}{|c|}{ I believe going to dentist would help my teeth } \\
\hline Strongly agree & $42.5(37.4-47.7)$ & Ref & - \\
\hline Somewhat agree or don't know & $44.1(31.2-57.6)$ & $1.03(0.76-1.41)$ & \\
\hline
\end{tabular}

$\mathrm{PR}$, prevalence ratio; APR: adjust prevalence ratio

${ }^{* * *} p<0.0001,{ }^{* *} p<0.001,{ }^{*} p<0.05$

${ }^{a}$ Univariable analysis without any adjustment

${ }^{\mathrm{b}}$ Reducing variable showing no statistical significance in univariable analysis and adjusting for remoteness, education level, and employment

Table 4 Prevalence ratio (PR) and 95\% Cl of self-reported gum disease and visiting dentist less than 1 year among women pregnant with an Indigenous child in South Australia $(n=427)$

\begin{tabular}{|c|c|c|c|}
\hline & $\%(95 \% \mathrm{Cl})$ & PR 95\% $\mathrm{Cl}^{\mathrm{a}}$ & APR $95 \% \mathrm{Cl}^{\mathrm{b}}$ \\
\hline \multicolumn{4}{|c|}{ Visiting dentist $<1$ year } \\
\hline No & $45.7(39.6-51.9)$ & Ref & Ref \\
\hline Yes & $37.4(29.6-45.8)$ & $0.82(0.64-1.04)$ & $0.95(0.86-1.05)$ \\
\hline
\end{tabular}

$\mathrm{PR}$, prevalence ratio; $\mathrm{APR}$, adjust prevalence ratio

${ }^{* * *} p<0.0001,{ }^{* *} p<0.001,{ }^{*} p<0.05$

${ }^{a}$ Univariable analysis without any adjustment

${ }^{\mathrm{b}}$ Reducing variable showing no statistical significance in univariable analysis and adjusting for remoteness, education level and employment

mainstream dental services include language and cultural barriers. Empirical research has demonstrated that awareness of dental service availability may be limited for some Indigenous people [21], and also midwives [41]. Making dental service systems more navigable is crucial, given the negative impacts that poor dental care utilisation on oral health outcomes.

For Indigenous Australians to better navigate dental care systems, information in accessible formats is required [42]. According to Robards [42], navigation systems that integrate technologies, such as social media, may facilitate Indigenous Australians to better understand, connect and engage with dental care. Such interventions should be based in the Indigenous community setting. During the COVID-19 crises, Summer noted [44] that the application of social media channels shared through trustworthy local community networks enabled fast and effective health information sharing. Although dental care service provision may not always be available in the Aboriginal Community Controlled Health Organisation setting, such organisations had an indispensable role in the dissemination of health information, and a leading role of enhancing communication among Indigenous communities [44].

Based on these findings, future navigation programs that embrace social media and related technology might be more effective and economically friendly for women pregnant with an Indigenous child. Such services should be easy to contact to make health system navigation more approachable and understandable. Navigation support is just one example of improving system navigation. The health navigator program-targeting both Indigenous and non-Indigenous Australians-was increasingly used 
among patients with chronic disease who have difficulties in accessing health service, which improved the process of care [45]. There is evidence [46, 47] that Indigenous Liaison Officers can improve the engagement of Aboriginal families with health professionals, and may have a positive impact on diagnosis. There are some Aboriginal Liaison Programs for dental care [48, 49], although no study specifically examined its effect on uptake of dental care, the project was proven to be successful in dental referral to mainstream dental service [49]. There has been a Midwifery-Initiated Oral Health Dental Service program. In this program, midwives provided oral assessments and referrals to local and free public dental care for pregnant women. The referral letter included the contact details of a dentist, a checklist of date of visit, number of visits and treatment to better navigate participants to the service and to facilitate them to complete the course of recommended treatment [50]. The program was effective and promising in the improved uptake of dental care, and may be a beneficial pathway forward to implement among Indigenous populations [51].

One of our study hypotheses was that participants who had a perceived need for dental care would have better oral health than their counterparts with no perceived need; however, this did not prove to be the case $(\mathrm{APR}=1.24,95 \% \mathrm{CI} 1.06-1.45)$. This suggests that the motivations or reason for participants' perceived need for dental care were mixed and complicated. For example, the last visit for a dental appointment may have been for a check-up (a good oral health-related behaviour) and because of a problem. Thus, "uptake of dental care within one year" was found to be a weak indicator for oral health outcome. "Reason for that last visit" would have been a more reliable indicator for the phenomenon we were aiming to measure.

Our study made it possible to compare aboriginal to non-aboriginal pregnant women. A higher demand for dental care among Aboriginal women during pregnancy can be observed in this study (85.8\%) compared with non-Aboriginal pregnant women in the United States (50.1\%) [52]. The rate of dental visit $<12$ months in this study (35.7\%) was very close to a comparable study in New Zealand (37.7\%) [19]. While it is still lower than non-Aboriginal pregnant women (45.6\%) [53], and figures from high income countries were more in dental attendance, with approximately $70-92 \%$ pregnant women reported to have accessed dental care in the last 12 months $[6,54]$.

This was the first study to describe dental uptake and service approachability, and to test the association with self-reported gum disease among women pregnant with an Indigenous child in Australia. Most of studies [27] focus on provision of transport and reduction of cost to improve the accessibility of health care for Aboriginal people. Little empirical research has focused on the phases before actual interaction with the health care service, including participant motivation and capability to contact the service. This study reiterates the importance of system navigation in accessing dental care, which might also give more directions to improve accessibility of primary health care for Indigenous people. Indications for future research include: (1) Dental health literacy on how to navigate dental systems is important in the access outcome of dental care. Navigation support could be integrated with technologies, based on local community networks and collaborating with midwives. (2) The effect that approachability of a given service has on health outcomes (dental attendance). Motivations for visiting a dentist differ, and this has an impact on oral health outcomes. Previous uptake of dental care was not a good indicator of oral health. There is a need for better analytical approaches, and different measures of exposures and outcomes to better illustrate the impact that utilisation of dental care has on oral health outcomes.

The study limitations were that social desirability bias may have influenced participant responses and no clinical data was collected to ascertain objective measures of dental health. This study was cross-sectional in design implying that no assumptions of causality could be made.

\section{Conclusion}

Although dental care was recognised as being important among our sample of women pregnant with an Indigenous child in South Australia, dental utilisation was low. Ability to successfully navigate the dental care system was associated with regular dental attendance. Perceived need for dental care was associated with self-reported gum disease. No association was observed between service-approachability-related factors and self-reported gum disease.

\section{Abbreviations}

APR: Adjust prevalence ratio; ARIA+: The Accessibility/Remoteness Index of Australia; PR: Prevalence ratio; ECC: Early childhood caries.

\section{Supplementary Information}

The online version contains supplementary material available at https://doi. org/10.1186/s12903-021-01816-5.

Additional file 1. Appendixes. Appendix A: Figure S1: A conceptual framework of access to health care [25]. Appendix B: Table S1: Questionnaire of factors impacting on dental service approachability. Appendix C: Figure S2: Variables corresponding to service-oriented model of accessing dental care. 


\section{Acknowledgements}

The authors gratefully acknowledge the support of Baby Teeth Talk (Australia) study participants, study staff and partners: the antenatal clinic of hospitals and Aboriginal Community Controlled Health Organisations in South Australia.

\section{Authors' contributions}

Data for the study is a part of the baseline data of an early childhood caries intervention among Indigenous children in South Australia (Original study). LMJ obtained the funding and design of the original study. In this study, YG was responsible for the study design, did the statistical analyses, produced the figures, interpreted the data and drafted the manuscript. LMJ and XJ are guarantors for this article. All authors contributed to data acquisition and interpretation, writing and completion of the manuscript. All authors critically reviewed and approved the manuscript. All authors read and approved the final manuscript.

\section{Funding}

This study was funded by the National Health and Medical Research Council of Australia (NHMRC, Project Grant 627350). LMJ is supported by a Senior Research Fellowship (NHMRC, Grant 1102587). The funder had no role in the design and conduct of the study; collection, management, analysis, and interpretation of the data; preparation, review, or approval of the manuscript; and decision to submit the manuscript for publication. LMJ had full access to all the data in the study and takes responsibility for the integrity of the data and the accuracy of the data analysis.

\section{Availability of data and materials}

Data cannot be shared publicly because of privacy issues of the participants. Data are available from the University of Adelaide Data Access (contact via Australian Research Centre for Population Oral Health: arcpoh@adelaide.edu. au) for researchers who meet the criteria for access to confidential data.

\section{Declarations}

\section{Ethics approval and consent to participants}

Ethics approval has been obtained from the University of Adelaide Human Research Ethics Committee (H-057-2010), the Aboriginal Health Council of South Australia (04-09-362), the Government of South Australia, the Human Research Ethics Committee of Child, Youth and Women's Health Service, and the Human Research Ethics Committees of participating Adelaide hospitals. The study was guided by an Indigenous reference group, World Health Organisation guidelines on ethical conduct in health research on Indigenous people, and local Indigenous South Australia principles. The study additionally used the Ethical Conduct in Aboriginal and Torres Strait Islander Health Research guidelines to obtain consent, and all participants were provided with an information sheet outlining the study objectives and signed an informed consent form (parents of the participants provided signed informed consent for those being under the age of 16 years) with $\$ 50$ voucher for reimbursement of time after completing the questionnaires.

\section{Consent for publication}

Not applicable.

\section{Competing interests}

The authors declare no competing interests.

\section{Author details}

${ }^{1}$ School of Public Health, The University of Adelaide, Adelaide, Australia. ${ }^{2}$ Australian Research Centre for Population Oral Health, Adelaide Dental School, The University of Adelaide, Adelaide, Australia.

Received: 12 November 2020 Accepted: 7 September 2021 Published online: 17 September 2021

\section{References}

1. AIATSIS. Indigenous Australians: Aboriginal and Torres Strait Islander people. AIATSIS. https://aiatsis.gov.au/explore/articles/indigenous-austr alians-aboriginal-and-torres-strait-islander-people. Published 2015. Accessed 22 Oct 2020.

2. Roberts-Thomson KF, Spencer AJ, Jamieson LM. Oral health of aboriginal and Torres strait islander Australians. Med J Aust. 2008;188(10):592.

3. Health Alo, Welfare: Australia's dental generations: the National Survey of Adult Oral Health 2004-06. In. Canberra: AlHW; 2007.

4. Wu M, Chen S-W, Jiang S-Y. Relationship between gingival inflammation and pregnancy. Mediators Inflamm. 2015;2015:623427-623427.

5. Figuero E, Carrillo-de-Albornoz A, Herrera D, Bascones-Martínez A. Gingival changes during pregnancy: I-influence of hormonal variations on clinical and immunological parameters. J Clin Periodontol. 2010;37(3):220-9.

6. Christensen LB, Jeppe-Jensen D, Petersen PE. Self-reported gingival conditions and self-care in the oral health of Danish women during pregnancy. J Clin Periodontol. 2003;30(11):949-53.

7. Dinas K, Achyropoulos V, Hatzipantelis E, Mavromatidis G, Zepiridis L, Theodoridis T, Dovas D, Tantanasis T, Goutzioulis F, Bontis J. Pregnancy and oral health: utilisation of dental services during pregnancy in northern Greece. Acta Obstet Gynecol Scand. 2007;86(8):938-44.

8. Page RC. Gingivitis. J Clin Periodontol. 1986;13(5):345-55.

9. Megson E, Fitzsimmons T, Dharmapatni K, Mark Bartold P. C-reactive protein in gingival crevicular fluid may be indicative of systemic inflammation. J Clin Periodontol. 2010;37(9):797-804.

10. Scannapieco F: Periodontal inflammation: from gingivitis to systemic disease? In: Compendium of continuing education in dentistry (Jamesburg, NJ: 1995); 2004, vol 25, no (7 Suppl 1), p. 16-25.

11. Contreras A, Herrera J, Soto J, Arce R, Jaramillo A, Botero J. Periodontitis is associated with preeclampsia in pregnant women. J Periodontol. 2006;77(2):182-8.

12. Canakci V, Yildirim A, Canakci CF, Eltas A, Cicek Y, Canakci H. Total antioxidant capacity and antioxidant enzymes in serum, saliva, and gingival crevicular fluid of preeclamptic women with and without periodontal disease. J Periodontol. 2007;78(8):1602-11.

13. Anil S, Anand PS. Early childhood caries: prevalence, risk factors, and prevention. Front Pediatr. 2017:5:157-157.

14. Correa-Faria P, Paixao-Goncalves S, Paiva SM, Pordeus IA. Incidence of dental caries in primary dentition and risk factors: a longitudinal study. Braz Oral Res. 2016;30:1.

15. Llena C, Calabuig E. Risk factors associated with new caries lesions in permanent first molars in children: a 5-year historical cohort follow-up study. Clin Oral Invest. 2018;22(3):1579-86.

16. Thomson WM, Williams SM, Broadbent JM, Poulton R, Locker D. Long-term dental visiting patterns and adult oral health. J Dent Res. 2010;89(3):307-11.

17. AlHW, S C, JE H, A E: Oral health and dental care in Australia: key facts and figures 2015. In: Canberra: AlHW; 2016.

18. Smith K, Kruger E, Dyson K, Tennant M. Oral health in rural and remote Western Australian indigenous communities: a two-year retrospective analysis of 999 people. Int Dent J. 2007;57(2):93-9.

19. Broughton J, Person M, Maipi J, Cooper-Te K, Smith-Wilkinson A, Tiakiwai S, Kilgour J, Berryman K, Morgaine K, Jamieson L. Ukaipo niho: the place of nurturing for oral health. NZ Dent J. 2014;110(1):18-23.

20. Jones K, Keeler N, Morris C, Brennan D, Roberts-Thompson K, Jamieson L. Factors relating to access to dental care for Indigenous South Australians. J Health Care Poor Underserved. 2016;27(1):148-60.

21. Shrivastava R, Couturier Y, Kadoch N, Girard F, Bedos C, MacDonald ME, Torrie J, Emami E. Patients' perspectives on integrated oral healthcare in a northern Quebec Indigenous primary health care organisation: a qualitative study. BMJ Open. 2019;9(7):e030005.

22. Campbell MA, Hunt J, Walker D, Williams R. The oral health care experiences of NSW Aboriginal Community Controlled Health Services. Aust N Z J Public Health. 2015;39(1):21-5.

23. Kong AC, Ramjan L, Sousa MS, Gwynne K, Goulding J, Jones N, Srinivas R, Rambaldini B, Moir R, George A: The oral health of Indigenous pregnant women: a mixed-methods systematic review. Women Birth. 2019.

24. Jamieson LM, Steffens M, Paradies YC. Associations between discrimination and dental visiting behaviours in an Aboriginal Australian birth cohort. Aust N Z J Public Health. 2013;37(1):92-3.

25. Levesque J-F, Harris MF, Russell G. Patient-centred access to health care: conceptualising access at the interface of health systems and populations. Int J Equity Health. 2013;12(1):18. 
26. Health Alo, Welfare: Australia's health 2018. In. Canberra: AlHW; 2018.

27. Davy C, Harfield S, McArthur A, Munn Z, Brown A. Access to primary health care services for Indigenous peoples: a framework synthesis. Int J Equity Health. 2016;15(1):163.

28. Broadbent JM, Zeng J, Foster Page LA, Baker SR, Ramrakha S, Thomson WM. Oral health-related beliefs, behaviors, and outcomes through the life course. J Dent Res. 2016;95(7):808-13.

29. Sivertsen N, Anikeeva O, Deverix J, Grant J. Aboriginal and Torres Strait Islander family access to continuity of health care services in the first 1000 days of life: a systematic review of the literature. BMC Health Serv Res. 2020;20(1):1-9.

30. Chuah FLH, Tan ST, Yeo J, Legido-Quigley H. The health needs and access barriers among refugees and asylum-seekers in Malaysia: a qualitative study. Int J Equity Health. 2018;17(1):120.

31. Merrick J, Chong A, Parker E, Roberts-Thomson K, Misan G, Spencer J, Broughton J, Lawrence H, Jamieson L. Reducing disease burden and health inequalities arising from chronic disease among Indigenous children: an early childhood caries intervention. BMC Public Health. 2012;12(1):323.

32. Jamieson LM, Smithers LG, Hedges J, Aldis J, Mills H, Kapellas K, Lawrence $H P$, Broughton JR, Ju X. Follow-up of an intervention to reduce dental caries in indigenous Australian children: a secondary analysis of a randomized clinical trial. JAMA Netw Open. 2019;2(3):e190648-e190648.

33. Health Alo, Welfare: The National Survey of Adult Oral Health 2004-06: South Australia. In. Canberra: AlHW; 2008.

34. World Health Organisation: Indigenous Peoples and Participatory Health Research. In: Geneva: World Health Organisation; 2003.

35. Council NHaMR: Ethical conduct in research with Aboriginal and Torres Strait Islander Peoples and communities: Guidelines for researchers and stakeholders. In. Edited by Council NHaMR. Canberra: Commonwealth of Australia; 2018.

36. Hugo Centre ADoHaA. Accessibility/Remoteness Index of Australia (ARIA+). Hugo Centre, Australian Department of Health and Ageing. https://www.adelaide.edu.au/hugo-centre/services/aria. Published 2016. Accessed 5 Jun 2020.

37. Consul P, Famoye F. Generalized Poisson regression model. Commun Stat Theory Methods. 1992;21(1):89-109.

38. Harris T, Yang Z, Hardin JW. Modeling underdispersed count data with generalized Poisson regression. Stand Genomic Sci. 2012;12(4):736-47.

39. Rocha JS, Arima LY, Werneck RI, Moyses SJ, Baldani MH. Determinants of dental care attendance during pregnancy: a systematic review. Caries Res. 2018;52(1-2):139-52.

40. Jones K, Keuskamp D, Brennan DS, Roberts-Thomson K: Understanding barriers and facilitators of access to dental care and completion of treatment for Aboriginal adults. 2016.

41. Riggs E, Yelland J, Shankumar R, Kilpatrick N. "We are all scared for the baby": promoting access to dental services for refugee background women during pregnancy. BMC Pregnancy Childbirth. 2016;16:12.

42. Robards F, Kang M, Steinbeck K, Hawke C, Jan S, Sanci L, Liew YY, Kong M, Usherwood T. Health care equity and access for marginalised young people: a longitudinal qualitative study exploring health system navigation in Australia. Int J Equity Health. 2019;18(1):41-41.
43. The National Advisory Council on Dental Health. REPORT OF THE NATIONAL ADVISORY COUNCIL ON DENTAL HEALTH. The National Advisory Council on Dental Health. Chapter Two-The Dental System Web site. https://www1.health.gov.au/internet/publications/publishing.nsf/ Content/report_nacdh report_nacdh_ch2. Published 2012. Accessed 31 Jan 2021.

44. Finlay S, Wenitong M. Aboriginal Community Controlled Health Organisations are taking a leading role in COVID-19 health communication. Aust N Z J Public Health. 2020;44(4):251-2.

45. McBrien KA, Ivers N, Barnieh L, Bailey JJ, Lorenzetti DL, Nicholas D, Tonelli M, Hemmelgarn B, Lewanczuk R, Edwards A, et al. Patient navigators for people with chronic disease: a systematic review. PLOS ONE. 2018;13(2):e0191980.

46. McKenna B, Fernbacher S, Furness T, Hannon M. Cultural brokerage and beyond: piloting the role of an urban Aboriginal Mental Health Liaison Officer. BMC Public Health. 2015;15(1):1-8.

47. Tavella R, McBride K, Keech W, Kelly J, Rischbieth A, Zeitz C, Beltrame JF, Tideman PA, Brown A. Disparities in acute in-hospital cardiovascular care for Aboriginal and non-Aboriginal South Australians. Med J Aust. 2016;205(5):222-7.

48. Dental health service victoria. Dental services for Aboriginal and Torres Strait Islander peoples. Dental health service victoria. https://www.dhsv. org.au/patients-and-public/aboriginal-services. Accessed 29 Oct 2020.

49. SA Dental Service. Aboriginal and Torres Strait Islander Programs. SA Dental Service. Aboriginal Liaison Program — South Australian Dental Service Web site. https://www.adelaide.edu.au/arcpoh/oral-health-promotion/ programs/focus-area/aboriginal-tsi/. Published 2005. Accessed 29 Oct 2020.

50. Johnson M, George A, Dahlen H, Ajwani S, Bhole S, Blinkhorn A, Ellis S, Yeo A. The midwifery initiated oral health-dental service protocol: an intervention to improve oral health outcomes for pregnant women. BMC Oral Health. 2015;15:2-2.

51. George A, Dahlen HG, Blinkhorn A, Ajwani S, Bhole S, Ellis S, Yeo A, Elcombe $E$, Johnson M. Evaluation of a midwifery initiated oral healthdental service program to improve oral health and birth outcomes for pregnant women: a multi-centre randomised controlled trial. Int J Nurs Stud. 2018;82:49-57.

52. Centers for Disease C, . Prevention: perceived health needs and receipt of services during pregnancy_Oklahoma and South Carolina, 2004-2007. MMWR Morb Mortal Wkly Rep. 2010;59(23):710-4.

53. George A, Johnson M, Blinkhorn A, Ajwani S, Bhole S, Yeo AE, Ellis S. The oral health status, practices and knowledge of pregnant women in south-western Sydney. Aust Dent J. 2013;58(1):26-33.

54. Timothe P, Eke PI, Presson SM, Malvitz DM. Dental care use among pregnant women in the United States reported in 1999 and 2002. Prev Chronic Dis. 2005;2(1):A10.

\section{Publisher's Note}

Springer Nature remains neutral with regard to jurisdictional claims in published maps and institutional affiliations.

Ready to submit your research? Choose BMC and benefit from:

- fast, convenient online submission

- thorough peer review by experienced researchers in your field

- rapid publication on acceptance

- support for research data, including large and complex data types

- gold Open Access which fosters wider collaboration and increased citations

- maximum visibility for your research: over $100 \mathrm{M}$ website views per year

At BMC, research is always in progress.

Learn more biomedcentral.com/submissions 